\title{
质子交换膜燃料电池超低铂化过程中物质传输的分析与 展望
}

程晓静 ${ }^{1}$, 沈水云 ${ }^{1}$, 王超 ${ }^{1}$, 间晓晖 ${ }^{1}$, 章俊良 ${ }^{1,2^{*}}$

1. 上海交通大学机械与动力工程学院, 燃料电池研究所, 上海 200240 ;

2. 上海交通大学, 动力机械与工程教育部重点实验室, 上海 200240

* 联系人, E-mail: junliang.zhang@sjtu.edu.cn

2021-02-04 收稿, 2021-05-08 修回, 2021-05-13 接受, 2021-05-14 网络版发表 国家重点研发计划(2016YFB0101312)和国家自然科学基金(21905172)资助

摘要 居高不下的成本已成为车用质子交换膜燃料电池商业化的最大阻碍. 其中, 用于阴极氧还原反应的Pt基贵金 属催化剂的成本占比最高, 降低Pt用量是控制燃料电池成本的关键. 然而, 一方面, Pt载量的降低会引起阴极氧气传 质阻力明显加大, 包括催化层纳米孔道内氧气扩散引起的体相传质阻力和氧气跨越Pt表面超薄离子树脂薄膜导致 的局域传质阻力, 从而引起电池性能的急剧恶化. 另一方面, 超低Pt膜电极中的质子传导问题也会降低电池的性能. 这是由于离子树脂薄膜的限域作用削弱了离子树脂内部的亲疏水相分离，减少了质子的传输通道和传递效率，造 成了较大的欧姆阻抗. 本文详细分析了Pt载量不断降低时, 阴极催化层内的氧气体相、局域传输以及质子传导规 律, 及其对电池性能的影响, 并针对其作用机制提出了应对策略.

关键词 超低Pt化, 阴极传质, 局域传质阻力, 体相传质阻力, 质子传导

燃料电池(fuel cell)不受卡诺循环限制，具有高 效、无污染、能量密度高等特点, 吸引了科学界和工 业界的广泛关注和持续投 ${ }^{[1,2]}$. 在众多类型的燃料电 池中, 质子交换膜燃料电池(proton exchange membrane fuel cells, PEMFCs)具有功率高、工作温度低、启动和 功率匹配迅速等优点, 被认为是最有希望取代内燃机 的动力系统. 目前, 车用PEMFCs 在效率、功率、能量 密度和冷启动等方面均已达到商业化要求 ${ }^{[3,4]}$, 如图 1 (a), (b)所示. 图1(c)展示了近20年来燃料电池成本的变 化, 虽然燃料电池成本具有明显的逐年下降趋势, 但距 离目标成本仍有较大距离. 值得注意的是, 根据国际氢 能委员会的测算, 燃料电池汽车的使用成本会随着行 驶里程的增加而缓慢增长, 其增长幅度远小于相同性 能的锂电池汽车. 如图1(d)所示, 行驶里程超过 $100 \mathrm{~km}$
后, 燃料电池汽车的优势将会凸显.

PEMFCs由膜电极(membrane electrode assemblies, MEAs)、气体扩散层(gas diffusion layers, GDLs)、双 极板及其他零部件组成, 各部分成本如图 1(e)所示. MEAs 是燃料电池的心脏, 由阴阳极催化层和质子交换 膜组成, 催化层中使用的催化剂是氧化还原反应的核 心. 虽然近年来非贵金属催化剂的性能得到不断突破, 但目前PEMFCs的催化剂仍是以Pt为主的贵金属或合 金(Pt-M)催化剂，催化剂的成本占到电堆成本的 $41 \%$ 以 上 $^{[3]}$. 值得注意的是, 与双极板、端板等部件不同, 催化 剂的成本不会随着产业规模的扩大而下降, 因此, 降低 燃料电池成本的关键是降低膜电极的Pt用量.

然而, 随着Pt载量的降低, 无论是使用 $\mathrm{Pt} / \mathrm{C}$ 催化剂 还是活性更高的Pt-M催化剂，电池的性能下降和寿命 

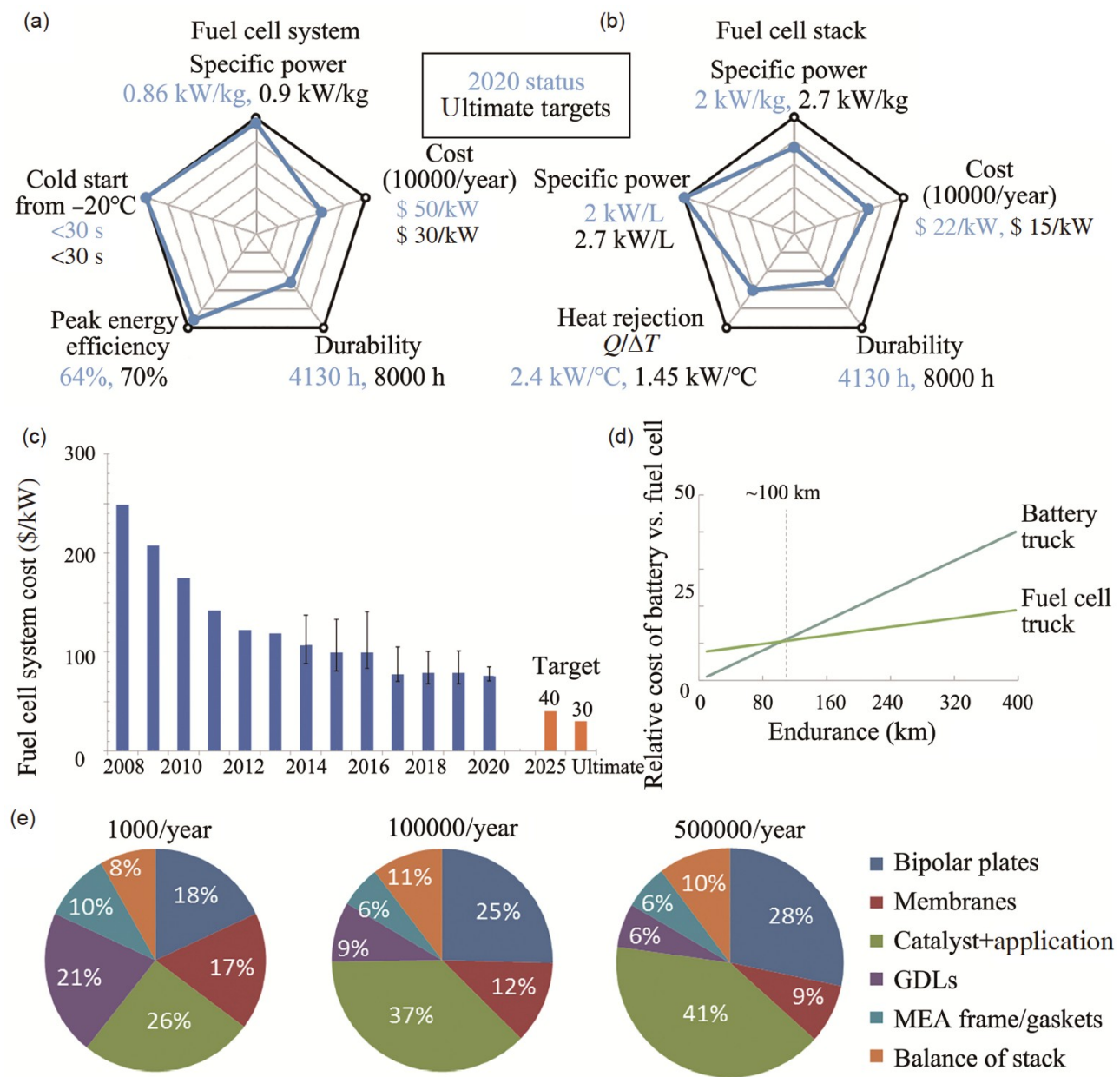

图 1 车用燃料电池现状. 燃料电池系统(a)和电堆(b)现状与最终目标的对比 ${ }^{[4]}$; (c) 燃料电池系统成本逐年下降 ${ }^{[5]}$; (d) 不同行驶里程下锂电池汽 车和燃料电池汽车的成本对比 ${ }^{[6]}$; (e) 年产量为 $1000 、 100000$ 和 500000 套机组时电堆的成本分解 ${ }^{[3]}$

Figure 1 Current status of vehicle fuel cells. Diagrams illustrating current status of automotive fuel cell systems (a) and stacks (b) relative to ultimate subprogram targets ${ }^{[4]} ;$ (c) cost of the fuel cell system decreases every year ${ }^{[5]} ;(d)$ costs of Li battery trucks vs. hydrogen trucks at different ranges ${ }^{[6]}$; (e) breakdown of fuel cell stack cost at 1000, 100000, and 500000 systems per year ${ }^{[3]}$

衰减都会明显加剧, 尤其在大电流密度(低电压)下的传 质极化区面临着更为严重的挑战. Kongkanand和 Mathias ${ }^{[7]}$ 发现, 当 Pt载量从 $0.2 \mathrm{mg} \mathrm{cm}^{-2}$ 降低到 $0.05 \mathrm{mg} \mathrm{cm}^{-2}$ 时, 电池在小电流密度区 $\left(0.2 \mathrm{~A} \mathrm{~cm}^{-2}\right)$ 的电 压降约为 $40 \mathrm{mV}$, 但在大电流密度区 $\left(2 \mathrm{~A} \mathrm{~cm}^{-2}\right)$ 却超过 $200 \mathrm{mV}$, 这在实际运用中是不可接受的. 显然, 质子交 换膜燃料电池阴极在低Pt和超低Pt载量下的传质规律 产生了明显的偏差. Kongkanand和Mathias ${ }^{[7]}$ 认为, 这种 偏差来自氧气到达Pt表面受到的局域传质阻力. 他们在 $0.05 \mathrm{mg} \mathrm{cm}^{-2} \mathrm{Pt}$ 载量条件下对这种阻力进行了补偿, 发 现降低或消除局域传质阻力后，电池性能有了明显 提升.

大量研究表明, 超低Pt载量下的电池性能偏差是由
催化层内氧气和质子传输不完全、不充分造成的，尤 其是大电流下，超低Pt化导致急速增大的局域氧气传 质阻力、缓慢的体相传质阻力和关键的质子传导阻力 是电池性能损失的最主要原因，也是限制新型催化剂 发挥原有效果的阻碍. 因此, 有必要查明氧气传质阻力 增大的原因和机理, 揭示催化层内的质子传导规律. 本 文总结了近年来在质子交换膜燃料电池超低Pt膜电极 中关于氧气和质子传输的关键成果，深人分析了传质 机理, 提出了具有科学性和可行性的优化策略, 为燃料 电池的大规模应用奠定了基础.

\section{1 低Pt膜电极阴极氧气传质动力学}

在质子交换膜燃料电池中，由于反应物传质缓慢 
导致的电池性能损失称为浓差极化损失，主要表现在 大电流密度区. 其中, 由于阳极的氢气扩散速率远高于 阴极, 浓差极化一般指阴极氧气传质损失. 在以往的高 Pt膜电极中, 由于催化位点丰富, 传质阻力造成的性能 损失并不明显. 然而, 随着Pt载量的降低, 氧气传质阻力 逐渐成为限制燃料电池性能的关键因素.

\section{1 阴极氧气传质阻力的构成}

如图2(a)所示，阴极的氧气首先在流道内以对流的 形式进行传质 ${ }^{[8]}$, 接着在浓度梯度的作用下穿过气体扩 散层, 向阴极催化层(cathode catalyst layers, CCLs)扩散, 然后在催化层内边扩散边反应. 根据关键部件的不同, 阴极氧气传质总阻力 $\left(R_{\mathrm{Total}}\right)$ 可以分为流道内的氧气传 质阻力 $\left(R_{\text {Channel }}\right)$ 、气体扩散层内的氧气传质阻力 $\left(R_{\mathrm{GDL}}\right)$ 和催化层内的氧气传质阻力 $\left(R_{\mathrm{CCL}}\right)^{[9]}$, 其关系式为

$R_{\text {Total }}=R_{\text {Channel }}+R_{\mathrm{GDL}}+R_{\mathrm{CCL}}$,

其中, $R_{\mathrm{Total}} 、 R_{\mathrm{Channel}} 、 R_{\mathrm{GDL}}$ 和 $R_{\mathrm{CCL}}$ 的单位均为 $\mathrm{s} \mathrm{cm}^{-1}$.

催化层氧气传质阻力又可以进一步细分. 如图2(b) 所示, 催化剂由碳颗粒 $(\sim 50 \mathrm{~nm})$ 和其负载的Pt或Pt-M合 金颗粒(2 5 nm)共同组成, 在催化剂表面又覆盖有一层 超薄的全氟磺酸(perfluorinated sulfonic acid, PFSA)离 子树脂薄膜 $(5 \sim 10 \mathrm{~nm})$. 催化层就是由大量这样的颗粒 团聚和堆积形成的多孔结构. 因此, 氧气首先在颗粒孔 隙间扩散, 然后渗透穿过催化剂表面的离子树脂超薄 膜到达Pt表面进行氧还原反应. 在这个过程中, 孔隙间 扩散过程的传质阻力被称为体相氧气传质阻力 (bulk oxygen transport resistance, $R_{\mathrm{Bulk}}$ ), 渗透通过PFSA离子
树脂薄膜的传质阻力被称为局域传质阻力 (local oxygen transport resistance, $R_{\text {Local }}$ ).

相比于催化层氧气传质, 学者对流场内氧气传质 和气体扩散层内氧气传质研究得更为充分. 其中, 流场 内的氧气传质研究一般以Fluent数值模拟和实验测试 相结合的方式展开 ${ }^{[10,11]}$. Yoon等人 ${ }^{[12,13]}$ 与Shimpalee和 Vanzee ${ }^{[14]}$ 均发现, 流场中的肋越窄, 流道中氧气传质越 好, 电池性能也会相应地提升. Wang等人 ${ }^{[15]}$ 对这一现 象进行了进一步解释, 较窄的肋会增强流场中的脊下 对流, 防止液态水的积累, 进而保证氧气传输通道的畅 通. 流场内氧气传质的另一个重要研究方向是三维流 场的设计, 如波浪形流场等 ${ }^{[16,17]}$, 可以通过流场底部的 起伏为反应气体增加一个法向的速度分量, 从而加速 氧气向催化层方向的扩散.

气体扩散层内的氧气传质多与孔隙结构和水热管 理相关 ${ }^{[18,19]}$. Ko 等人 ${ }^{[20]}$ 指出, 当气体扩散层内的孔隙梯 度增加时, 电极中的液态水含量会相应降低, 从而促进 氧气传质, 提高电池性能. Chen等人 ${ }^{[21]}$ 发现, 聚四氟乙 烯(polytetrafluoroethylene, PTFE)的添加可以提高气体 扩散层的疏水性和热传导性, 进而影响电池性能.

\section{2 体相和局域传质阻力的实验研究进展}

测量催化层传质阻力首先要测量阴极总阻力, 最 常见的方法是极限电流法. 极限电流 $\left(i_{\mathrm{lim}}\right)$ 指的是在氧 气浓度的限制下燃料电池所能达到的最大电流. 此时, 催化剂表面的氧气浓度 $\left(c_{\mathrm{O}_{2}}^{\mathrm{Pt}}\right)$ 为 0 . 根据法拉第定律和菲 克第一定律, 在极限电流状态下可以得到:
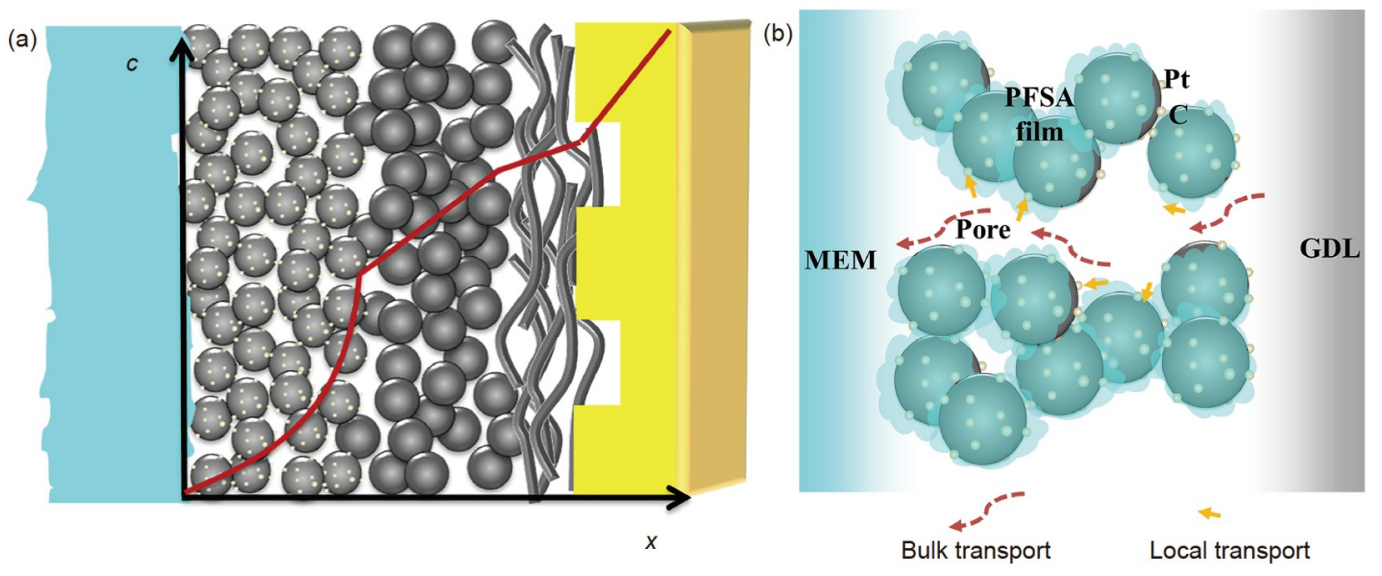

图 2 阴极催化层氧气传质. (a) 氧气在阴极各关键部件中的浓度分布; (b) 阴极催化层结构示意图及两类传质阻力

Figure 2 Oxygen transport in CCLs. (a) Oxygen concentration profile in the key components of cathode; (b) representation of the CCL structure and two types of mass transport behavior 
$R_{\text {Total }}=n F \frac{c_{\mathrm{O}_{2}}^{\text {Channel }}-c_{\mathrm{O}_{2}}^{\mathrm{Pt}}}{i_{\lim }}=n F \frac{c_{\mathrm{O}_{2}}^{\text {Channel }}}{i_{\lim }}$,

其中, $n$ 为反应电子数, 在氢氧燃料电池中 $n$ 取 $4 ; F$ 为

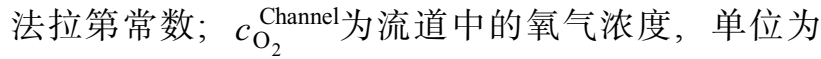
$\mathrm{mol} \mathrm{cm}{ }^{-3}$.

如果进一步将流场和气体扩散层内的氧气传质阻 力从阴极总阻力中扣除, 就可以得到催化层内的氧气 传质阻力. Baker等人 ${ }^{[9]}$ 给出了流场内氧气传质阻力的 计算式:

$R_{\text {Channel }}=A \frac{a}{D_{\mathrm{O}_{2}}^{\mathrm{CH}}}+B \frac{2 N d L}{Q_{\text {dry }}}\left(\frac{273}{T}\right) \frac{P-P_{\mathrm{w}}}{P_{\mathrm{a}}}$,

其中, $A$ 和 $B$ 为经验参数; $a 、 L$ 和 $d$ 分别表示流场槽宽的 一半、流道长度和流道槽深, 单位为 $\mathrm{cm} ; N$ 为流道根数; $D_{\mathrm{O}_{2}}^{\mathrm{CH}}$ 为流道中的氧气扩散系数, 单位为 $\mathrm{cm}^{2} \mathrm{~s}^{-1} ; P 、 P_{\mathrm{a}}$ 和 $P_{\mathrm{w}}$ 分别为流道内的气体压力、大气压力和水蒸气分 压, 单位为 $\mathrm{kPa} ; T$ 为电池工作温度, 单位为 $\mathrm{K}$.

实际使用中的气体扩散层以碳纸的形式存在，由 一层碳纤维交织组成的碳支撑层和一层由碳颗粒堆叠 而成的微孔层(micro pore layer, MPL)组成. 根据气体扩 散层的结构特点, Wang等人 ${ }^{[22]}$ 提出了一个简单、有效 的方法来测量气体扩散层内的氧气传质阻力. 他们在 控制气体扩散层压缩率不变的条件下改变碳纸的层数, 通过对阴极总传质阻力线性回归得到气体扩散层内的 氧气传质阻力, 计算式如下:

$R_{\mathrm{GDL}}=R_{\text {Total, } n+1 \text { carbon papers }}-R_{\text {Total, } n \text { carbon papers }}$,

其中, $R_{\text {Total, } n+1 \text { carbon papers }}$ 和 $R_{\text {Total, } n \text { carbon papers }}$ 的单位均为 $\mathrm{s} \mathrm{cm}^{-1}$.

结合式(1) (4), 可以得到:

$R_{\mathrm{CCL}}=4 F \frac{c_{\mathrm{O}_{2}}^{\mathrm{CH}}}{i_{\mathrm{lim}}}-A \frac{a}{D_{\mathrm{O}_{2}}^{\mathrm{CH}}}-B \frac{2 N d L}{Q_{\mathrm{dry}}}\left(\frac{273}{T}\right) \frac{P-P_{\mathrm{w}}}{P_{\mathrm{a}}}-R_{\mathrm{GDL}}$.

长久以来，众多科学家致力于催化层氧气传质阻 力的研究. 然而, 由于催化层结构复杂, 孔隙结构涵盖 大孔( $>50 \mathrm{~nm})$ 、介孔(2 50 nm) 和微孔(0.7 2 nm), 同时 体相和局域传质阻力耦合作用, 难以量化区分, 使得研 究进展缓慢. Mashio等人 ${ }^{[23]}$ 提出, 可以通过改变反应气 体的压力将传质阻力分为受压力影响部分和不受压力 影响部分, 并把后者命名为其他传质阻力 $\left(R_{\text {other }}\right)$. 进一 步地，该研究小组提出了“传输线”模型用来解释该阻
力, 认为催化层内的氧气传质阻力可以分为宏观阻力 $\left(R_{\mathrm{O}_{2}, \text { CCL-macro }}\right)$ 、微观阻力 $\left(R_{\mathrm{O}_{2}, \text { CCL-micro }}\right)$ 和受压力影响的 阻力 $\left(R_{\mathrm{P}}\right)$. 其中, $R_{\mathrm{P}}$ 来源于氧气的分子扩散, 可以通过变

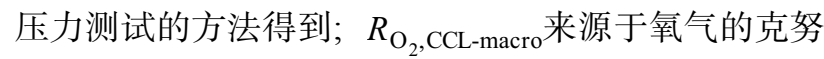
森扩散，可以根据理论公式计算得到; 拟合计算得到 $R_{\mathrm{O}_{2}, \text { CCL-micro }}{ }^{[24-26]}$. 然而, 克努森扩散系数的计算严重依 赖催化层孔结构的精确测量, 可能会给实验带来不容 忽视的误差. Nonoyama等人 ${ }^{[27]}$ 认为, 催化层内的氧气 扩散以克努森扩散为主，受温度影响如式(6)所示，而 氧气在PFSA离子树脂中的渗透受温度影响如式(7)所 示. 因此, 可以通过拟合催化层阻力 $\left(R_{\mathrm{CCL}}\right)$ 与温度 $T$ 的函 数关系, 得到体相与局域传质阻力. 然而, 这种方法也 存在一定的局限性: 一方面, 由于催化层孔隙结构的复 杂性, 体相传质也包含少量的分子扩散, 不能用简单的 克努森扩散公式进行概括; 另一方面, 二者对于温度的 敏感性相差并不十分明显, 容易带来实验误差.

$$
\begin{aligned}
D_{\text {Knud,A }}= & \frac{2}{3} r_{\text {Knud }} \sqrt{\frac{8 R T}{\pi M_{\mathrm{A}}}}, \\
\psi_{\text {ion, } \mathrm{O}_{2}}= & 3.27 \times 10^{-15} \exp [1.28(R H)] \\
& \times \exp \left[\frac{17200}{R}\left(\frac{1}{323.15}-\frac{1}{T}\right)\right],
\end{aligned}
$$

其中, $D_{\text {Knud,A }}$ 为 $\mathrm{A}$ 分子的克努森扩散系数, 单位为 $\mathrm{cm}^{2} \mathrm{~s}^{-1}$; $r_{\mathrm{Knud}}$ 为孔径, 单位为 $\mathrm{cm} ; R$ 为气体常数, $M_{\mathrm{A}}$ 为 $\mathrm{A}$ 分子的分 子质量; $\psi_{\mathrm{ion}, \mathrm{O}_{2}}$ 为氧气在PFSA离子树脂中的渗透率.

Greszler等人 ${ }^{[28]}$ 经过严格的数学推导，得到了催化 层阻力与催化层内氧气有效扩散系数 $\left(D_{\mathrm{O}_{2}}^{\text {eff }}\right)$ 和局域传 质阻力的关系:

$R_{\mathrm{CCL}}=\frac{r_{\mathrm{Local}}}{f_{\mathrm{Pt}}}(h / \varphi) \operatorname{coth}(h / \varphi)$,

其中, $r_{\mathrm{Local}}$ 为单位 $\mathrm{Pt}$ 表面积上的局域传质阻力; $h$ 为电极 厚度, 单位为 $\mathrm{cm} ; f_{\mathrm{Pt}}$ 为电极的粗鉌度系数, 是电极上的 电化学活性面积与电极面积的比值, $R_{\mathrm{Local}}=\frac{r_{\mathrm{Local}}}{f_{\mathrm{Pt}}} \varphi \varphi=$ $\sqrt{D_{\mathrm{O}_{2}}^{\text {eff }} \frac{h r_{\text {Local }}}{f_{\mathrm{Pt}}}}$.

经过计算得出, 当 $h / \varphi \rightarrow 0$, 即 $h / D_{\mathrm{O}_{2}}^{\text {eff }} \rightarrow 0$ 时, 式(8) 可以写作:

$R_{\mathrm{CCL}} \approx \frac{r_{\text {Local }}}{f_{\mathrm{Pt}}}$.

因此，可以制备不同 $\mathrm{Pt}$ 载量的膜电极，通过 $R_{\mathrm{CCL}}$ 和 
$f_{\mathrm{Pt}}$ 线性关系的斜率得到局域传质阻力. 在很长一段时间 内, 这种方法得到了包括通用汽车公司 ${ }^{[29]}$ 、Gasteiger 课题组 ${ }^{[30]}$ 和Weber课题组 ${ }^{[31]}$ 等的认可. 然而, 式(9)是建 立在有效扩散系数无穷大的假设之上, 并不能准确地 与事实相符. 此外, 该测试方法误差较大, 难以测试不 同膜电极间的细微差别.

Zhang课题组 ${ }^{[22]}$ 提出了一种全新的量化区分体相 和局域传质阻力的方法, 开创性地设计了一种双层结 构的阴极. 如图3(a)所示, 该双层阴极结构由一层较薄 的具有催化活性的催化层和一层较厚的不具有催化活 性的类催化层(dummy catalyst layer, DCL)组成. 在这种 情况下, 式(1)可以写作:

$R_{\text {Total }}=R_{\text {Channel }}+R_{\mathrm{GDL}}+R_{\mathrm{DCL}}+R_{\mathrm{CCL}}$,

其中, $R_{\mathrm{DCL}}$ 为类催化层内的氧气传质阻力, 单位为 $\mathrm{s} \mathrm{cm}^{-1}$. 由于类催化层和催化层采用相同的碳载体材料 和制备工艺, 二者具有相同的孔隙结构. 可以认为, 类 催化层内的氧气传质阻力与催化层内的体相传质阻力 相同; 而由于类催化层内没有活性位点, 氧气只会发生 扩散而不会发生在离子树脂中的渗透，因此类催化层 内的氧气传质阻力不包括局域传质阻力. 另外, 在双层 阴极结构设计中, 需要保证类催化层厚度 $\left(h_{\mathrm{DCL}}\right)$ 远大于 催化层厚度 $\left(h_{\mathrm{CCL}}\right)$, 那么催化层内的体相传质阻力可以 忽略不计. 式(10)可以写作:

$R_{\text {Total }}=R_{\text {Channel }}+R_{\mathrm{GDL}}+R_{\text {Bulk }}+R_{\text {Local }}\left(h_{\mathrm{DCL}} \gg h_{\mathrm{CCL}}\right)$.

进一步地，体相传质阻力与类扩散层厚度成正比， 式(11)与(2)结合可以写作:

$$
\begin{aligned}
\frac{1}{i_{\text {lim }}}= & \frac{r_{\text {Bulk }}}{n F c_{\mathrm{O}_{2}}^{\text {Channel }}} h_{\mathrm{DCL}} \\
& +\frac{1}{n F c_{\mathrm{O}_{2}}^{\text {Channel }}}\left(R_{\text {Channel }}+R_{\mathrm{GDL}}+R_{\text {Local }}\right),
\end{aligned}
$$

其中, $r_{\mathrm{Bulk}}$ 是单位厚度催化层内的体相传质阻力, 单位 为 $\mathrm{s} \mathrm{cm}^{-2}$.

从式(12)可以看出, 极限电流的倒数与类催化层厚 度呈线性关系. 通过测试不同厚度催化层的极限电流, 并对其结果进行线性回归，如图3(b)所示，就可以根据 斜率求得体相传质阻力, 根据截距求得局域传质阻力. 利用这种方法, Zhang课题组 ${ }^{[2]}$ 定量分析了低Pt膜电极 中的体相和局域传质阻力, 发现当 $\mathrm{Pt}$ 载量降低到 $0.05 \mathrm{mg} \mathrm{cm}^{-2}$ 时, 局域传质阻力占催化层总阻力的 $77 \%$. 结果表明, 随着Pt载量的降低, 局域传质阻力的影响逐 渐凸显, 成为改善电堆性能面临的最大困难.

\section{3 氧气局域传质机理研究}

在更为微观的角度上, 根据“吸附-扩散”理论, 局域 传质可以被分为 3 个步骤: 氧气在离子树脂表面(gas/ionomer interface)的吸附、在离子树脂内部的扩散和在 Pt表面(ionomer/Pt interface)的吸附, 如图4(a), (b)所示.

Kudo等人 ${ }^{[33 \sim 38]}$ 针对局域传质开展了一系列研究, 对局域传质的过程进行了简化和数学描述, 如图4(c)所 示. 根据理想气体状态方程, 气相中的氧气浓度 $\left(c_{\mathrm{gas}}\right)$ 可 以写作:

$c_{\text {gas }}=\frac{p_{\mathrm{O}_{2}}^{\text {ext }}}{R T}$,

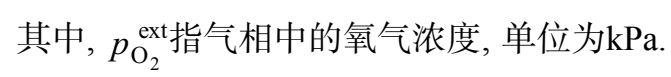

(a)

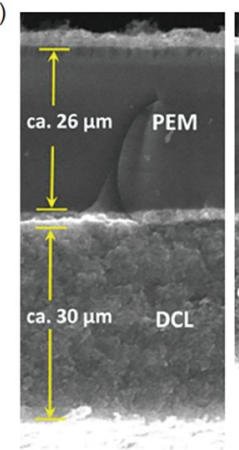

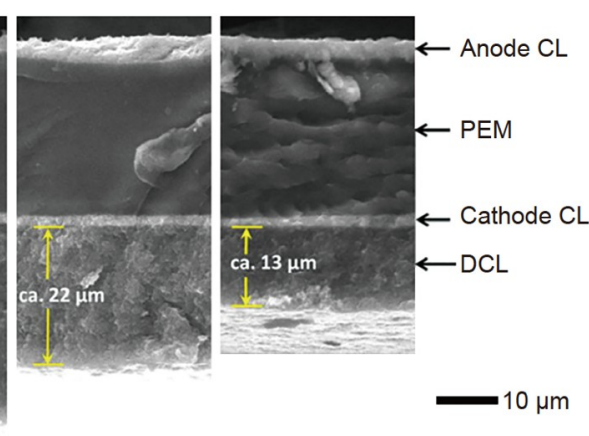

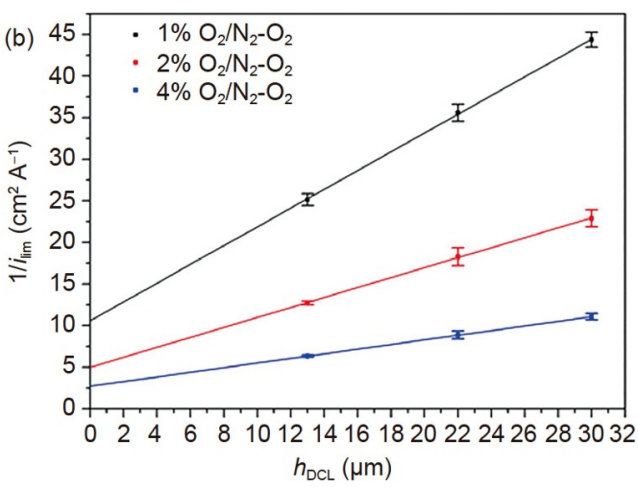

图 3 阴极催化层氧气传质阻力测试. (a) 具有不同厚度类阴极催化层双层电极结构的扫描电子显微镜图像; (b) 极限电流的倒数与类催化层厚 度的函数关系 ${ }^{[22]}$

Figure 3 Measurement of oxygen transport resistance in CCLs. (a) The cross-sectional SEM images of dual-layer CCLs with different DCL thicknesses; (b) relationship between $1 / i_{\lim }$ and DCL thickness ${ }^{[22]}$ 

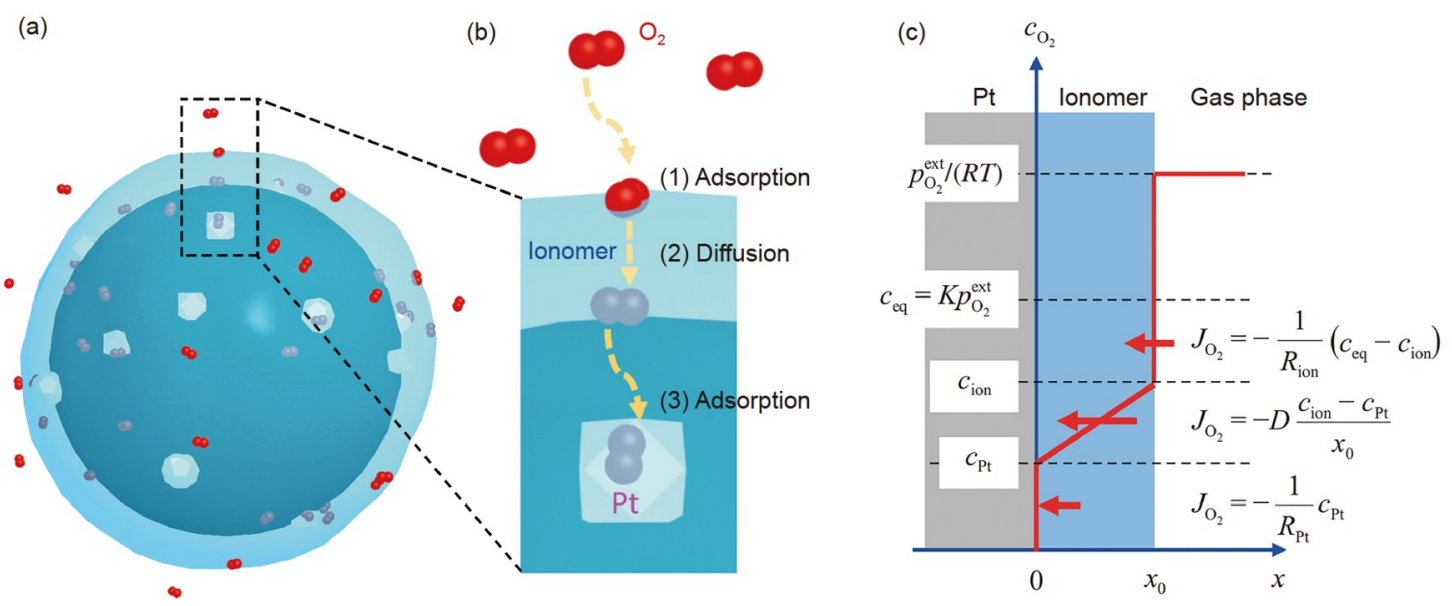

图 4 局域氧气传质. (a), (b) 局域传质步骤的示意图 ${ }^{[32]}$; (c) 离子树脂薄膜中的氧气浓度变化示意图 ${ }^{[33]}$

Figure 4 Local oxygen transport. (a), (b) Schematic illustration on the local transport processes ${ }^{\text {[32] }}$; (c) oxygen concentration profile in ionomer film ${ }^{[33]}$

根据氧气在离子树脂表面吸附的热力学, 可以写 出氧气平衡浓度 $c_{\mathrm{eq}}$ :

$c_{\mathrm{eq}}=K p_{\mathrm{O}_{2}}^{\mathrm{ext}}$,

其中, $K$ 为氧气在PFSA离子树脂表面的吸附率, 单位为 $\mathrm{mol} \mathrm{cm}{ }^{-3} \mathrm{kPa}^{-1}$.

进一步地，可以分别写出氧气在离子树脂表面吸 附、在离子树脂内部扩散和在Pt表面吸附的气体通量 方程:

$J_{\mathrm{O}_{2}}=-\frac{1}{R_{\text {ion }}}\left(c_{\text {eq }}-c_{\text {ion }}\right)$,

$J_{\mathrm{O}_{2}}=-D_{\mathrm{O}_{2}}^{\text {ion }} \frac{c_{\text {ion }}-c_{\mathrm{Pt}}}{x_{0}}$,

$J_{\mathrm{O}_{2}}=-\frac{1}{R_{\mathrm{Pt}}} c_{\mathrm{Pt}}$,

其中, $J_{\mathrm{O}_{2}}$ 为氧气通量, 单位为 $\mathrm{mol} \mathrm{s} \mathrm{s}^{-1} \mathrm{~cm}^{-2}$, 在 3 个步骤 中保持一致; $R_{\mathrm{ion}}$ 和 $R_{\mathrm{Pt}}$ 分别为氧气在离子树脂表面和 $\mathrm{Pt}$ 表面吸附的界面阻力, 单位为 $\mathrm{s} \mathrm{cm}^{-1} ; D_{\mathrm{O}_{2}}^{\text {ion 为氧气在离 }}$ 子树脂内部的扩散系数, 单位为 $\mathrm{cm} \mathrm{s}^{-2} ; c_{\text {ion }}$ 和 $c_{\mathrm{Pt}}$ 分别为 离子树脂表面和Pt表面的氧气浓度.

结合式(14) (17), 可以得到单位Pt表面积上的局域 传质阻力:

$r_{\text {Local }}=\frac{1}{K R T}\left[\frac{x_{0}}{D_{\mathrm{O}_{2}}^{\text {ion }}}+\left(R_{\text {ion }}+R_{\mathrm{Pt}}\right)\right]$.

值得注意的是，催化剂表面的PFSA离子树脂超薄 膜只有 5 10 nm, 不同于微米级别的质子交换膜. 在这
层纳米级别的超薄膜中, 由于薄膜厚度的限制, 吸附步 骤占主导地位, 更多地影响着氧气的局域传质. 这一理 论也得到了学术界的普遍认可和广泛验证 ${ }^{[32,38,39]}$. 因 此, 式(18)中的氧气在PFSA离子树脂表面的吸附率 $K$ 是 一个至关重要的参数, 它决定了氧气在离子树脂上的 吸附能力. 在以往的认知中, 通常用亨利定律来描述这 个过程, 即吸附率是一个定值, 不受周围氧气浓度的影 响. 然而, Shen等人 ${ }^{[32]}$ 提出了不同的意见，他们通过实 验发现, 当改变电池运行的氧气浓度条件时, 氧气吸附 率会随氧浓度的增大而减小，即氧气局域传质阻力随 氧浓度增大而增大. 这是因为离子树脂表面的吸附位 点是有限的，随着氧气浓度的增加，氧气吸附量会增 加，更多位点被氧气占据，吸附位点趋于饱和，导致吸 附率的下降，所以氧气在离子树脂表面的吸附不会呈 线性分布, 而会呈近对数分布.

Shen等人 ${ }^{[32]}$ 也研究了其他运行条件对局域传质的 影响，发现局域传质阻力随电池工作温度和反应气体 相对湿度(relative humidity, RH)的增大而减小, 随反应 气体压力的增大而增大. 这可能与离子树脂内的亲疏 水域分布和气体分子竞争吸附有关. 关于相对湿度的 影响, Kudo等人 ${ }^{[37]}$ 也得到了类似的结论. 此外, 他们发 现，局域传质中的界面传质阻力和扩散传质阻力均会 随相对湿度的增大而减小. 然而，Iden等人 ${ }^{[26]}$ 却发现， 氧气局域传质阻力在低湿度下随相对湿度的增大而减 小, 在高湿度下随相对湿度的增大而增大. 有研究发现, 氧气在离子树脂中的渗透率随水含量的增大而降

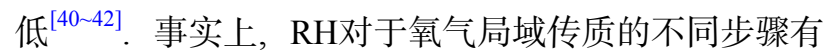


着不同的影响. 众多研究发现, RH的增大会削弱氧气 在离子树脂表面的吸附, 但会增强氧气在离子树脂内 部的扩散 ${ }^{[43-45]}$, 因此RH对于局域传质的影响十分复杂, 需要综合考虑多方面的影响. 此外, 相对湿度不仅会影 响离子树脂薄膜本身的形貌分布和氧气的传质性质, 在较高湿度和大电流运行条件下，还可能导致氧还原 反应产生的水分子不能及时排出，在催化剂和离子树 脂薄膜中间形成一层更薄的超薄水膜，增大局域传质 阻力 ${ }^{[32]}$. 这可能就是不同研究得到不尽相同的观测结 果的原因.

除了多变的运行环境, 燃料电池催化层中复杂的 结构也显著影响着氧气局域传质, 影响最为明显的是 离子树脂含量. 催化层中的离子树脂含量通常用树脂 与碳载体的质量比(ionomer/carbon, $I / C$ )来表示. Chowdhury等人 ${ }^{[46]}$ 通过实验发现, 离子树脂含量越高, 氧气局域传质阻力越大. 他们认为, 这是由催化剂表面 的离子树脂薄膜的厚度增加造成的. 然而, Wang等 人 $^{[47]}$ 对此现象作了进一步的分析, 发现当 $I / C$ 从 0.65 增
加到 0.95 时，局域传质阻力增加了 10 倍，远大于离子树 脂薄膜厚度增加所能导致的阻力增加. 因此可以推断, 厚度增加并不是离子树脂增加造成的唯一影响. Wang 等人 ${ }^{[47]}$ 认为，局域传质阻力对于离子树脂含量的高敏 感性来自树脂形貌的根本性改变, 离子树脂会在催化 层内形成胶团、团聚，甚至堵塞孔道结构. 如图5(a)所 示, 这种形貌的复杂改变导致了局域传质阻力的迅速 增大.

此外, PFSA离子树脂本身的性质也会影响局域传 质. PFSA离子树脂的当量质量(equivalent weight, EW) 是指含有 $1 \mathrm{~mol} \mathrm{SO}_{3}{ }^{-}$干树脂的质量, 用于表征离子树脂 的离子交换能力，是树脂离子交换容量(ion exchange capacity, IEC)的倒数. Ono等人 ${ }^{[42]}$ 发现, 随着EW的增 加，局域传质阻力会降低. Katzenberg等人 ${ }^{[48]}$ 通过在 PFSA离子树脂的主链上加人一种无定形的全氟甲基 环戊烷基团(perfluoro(2-methylene-4-methyl-1,3-dioxolane), PFMMD), 如图5(b)所示, 降低了PFSA离子树脂 薄膜内的结晶度, 帮助氧气快速传输, 有效降低了局域 (a)

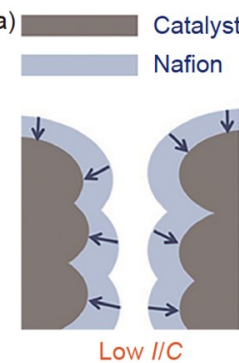

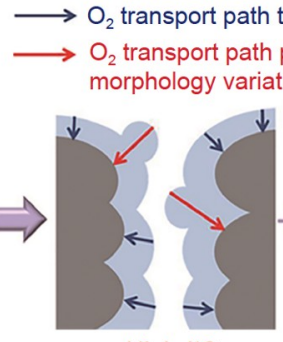

High $/ / C$

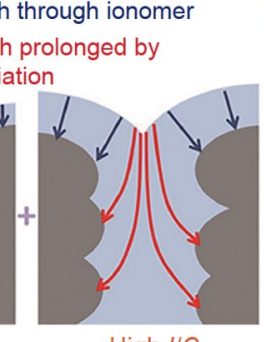

High //C (b) PTFE-based PFSAs

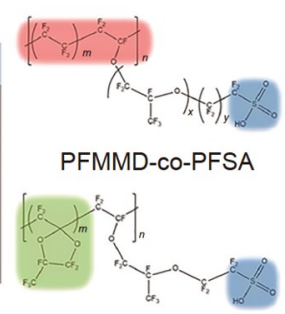

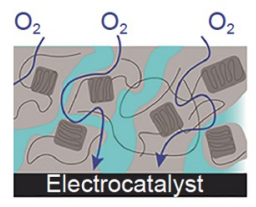

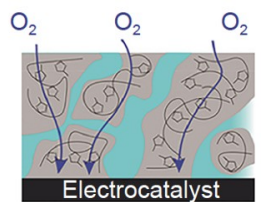

(c)

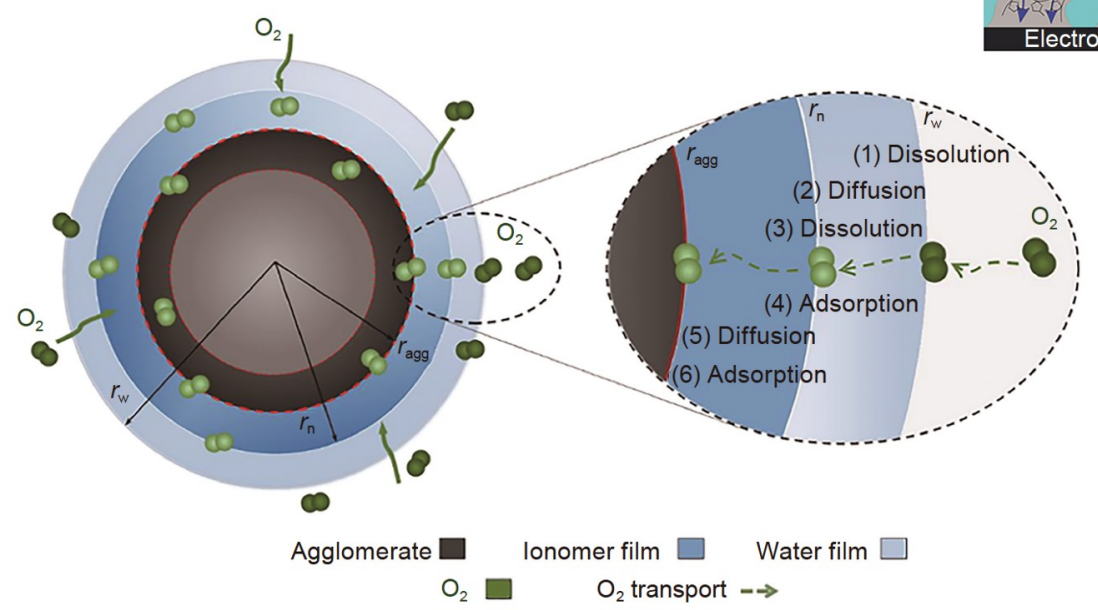

图 5 局域氧气传质阻力. (a) 离子树脂含量对局域传质的影响 ${ }^{[47]}$; (b) 不同主链结构的离子树脂(Nafion和PFMMD-co-PFSA)结构式及其内部的 氧气传质过程示意图 ${ }^{[48]}$; (c) 高湿度条件下阳极催化层中局域氧气传质阻力示意图 ${ }^{[5]}$

Figure 5 Local oxygen transport resistance. (a) Effects of ionomer content on local transport process ${ }^{[47]}$; (b) chemical structures of ionomer with different backbone structures (Nafion and PFMMD-co-PFSA) and the corresponding oxygen transport mechanism ${ }^{[48]}$; (c) schematic of local oxygen transport resistance in cathode catalyst layer under high $\mathrm{RH}$ condition ${ }^{[56]}$ 
传质阻力.

同时，催化剂碳载体的表面性质会改变PFSA离子 树脂的分布状态，进而影响氧气的局域传质阻力. Cheng等人 ${ }^{[49]}$ 发现, 使用不同碳载体的催化剂表面的局 域传质阻力差距可达3倍以上. Orfanidi等人 ${ }^{[30,50]}$ 通过在 碳载体表面修饰含氮官能团，改变了离子树脂的分布， 大幅降低了局域传质阻力. 另外, Pt颗粒在碳载体表面 的几何分布也会影响局域传质阻力. Owejan等人 ${ }^{[29]}$ 发 现，Pt颗粒在碳载体表面分布越均匀，局域传质阻力越 小. Sun等人 ${ }^{[51]}$ 也报道了类似的现象，他们认为是单位 $\mathrm{Pt}$ 表面积上产生的大量产物水在催化剂表面形成了超 薄水膜, 进而增大了局域传质阻力并影响了电池性能.

此外, 随着多孔碳, 也就是高比表面碳(high surface carbon，HSC)在PEMFC催化剂制备中的广泛应用 ${ }^{[52] \text {, }}$ 研究发现, 当Pt颗粒在HSC上沉积时, 会优先选择沉积 在碳表面的微孔中 ${ }^{[53,54]}$ ，这就对局域传质的理解提出 了新要求.Mashio等人 ${ }^{[55]}$ 建立了针对多孔碳的局域传 质模型：对于沉积在碳载体表面的Pt颗粒，其氧气局域 传质阻力 $\left(r_{\text {Local out }}\right)$ 与固体碳表面的局域传质机理类似; 而对于沉积在碳载体孔内的Pt颗粒, 氧气需要先在孔内 进行克努森扩散, 再渗透通过Pt颗粒表面的水膜, 氧气 局域传质阻力 $\left(r_{\text {Local,in }}\right)$ 更大. 而总的局域传质阻力为二 者并联的结果, 即 $\left(\frac{1}{r_{\text {Local,out }}}+\frac{1}{r_{\text {Local, in }}}\right)^{-1}$.

同时, 当电池在高湿度工况下运行时, 在催化剂团 聚的表面会产生一层水膜，对局域氧气传质产生影响. Liang等人 ${ }^{[56]}$ 提出了一种1D-2D稳态超空间团聚模型对 这种情况进行描述. 如图 5(c)所示, 该模型包括一个1D 的局域氧气传质亚模型和一个 $2 \mathrm{D}$ 的两相多组分 PEMFC亚模型，可以很好地模拟高湿度条件下的催化 层局域传质阻力.

\section{4 氧气体相传质机理}

由于质子交换膜燃料电池催化层中的孔道均为纳 米级别的微观结构, 氧气在催化层内的体相扩散传质 也造成了可观的浓差极化损失，引起了研究者的兴趣 一般来说，氧气的体相传质用催化层内的氧气有效扩 散系数表示, 即单位厚度上体相扩散阻力的倒数:

$D_{\mathrm{O}_{2}}^{\text {eff }}=\frac{1}{r_{\text {Bulk }}}$.

在传统的多孔材料流体传质中，有效扩散系数通
常用Bruggeman近似表示 ${ }^{[57,58]}$, 这种方法也被广泛应用 于质子交换膜燃料电池催化层内气体扩散系数的估算, 尤其是在模拟计算领域 ${ }^{[59,60]}$. Bruggeman近似的表达式 如下:

$D_{\mathrm{O}_{2}}^{\text {eff }}=D_{\mathrm{O}_{2}} \varepsilon^{(n+1) / n}$,

其中, $D_{\mathrm{O}_{2}}$ 为自由空间内的氧气扩散系数, $\varepsilon$ 为催化层内 的孔隙率, $n$ 为形状因子, 由于催化层颗粒被近似看作 球状模型, 在本式中 $n=2^{[61]}$.

然而, 随着研究的逐步深人, 人们越来越发现这个 近似公式难以匹配实验的测量结果. Shen等人 ${ }^{[62]}$ 使用 一个自制的Loschmidt扩散电池，测得催化层内的氧气 有效扩散系数为 $(1.47 \pm 0.05) \times 10^{-7} \mathrm{~m}^{2} \mathrm{~s}^{-1}$, 并认为催 化层内的氧气-氮气二元扩散主要受克努森扩散的支 配. Yu等人 ${ }^{[63,64]}$ 使用石墨碳和无定形碳分别制备了含 有不同离子树脂含量的催化层，发现氧气有效扩散系 数在 $0.09 \times 10^{-6} \sim 2.41 \times 10^{-6} \mathrm{~m}^{2} \mathrm{~s}^{-1}$ 之间, 碳载体形貌 对体相传质有重要影响. 类似的结论也被Cheng等人 ${ }^{[49]}$ 报道过, 他们基于 3 种不同类型的碳载体制备了催化层, 并测试了催化层内的氧气有效扩散系数, 分别为 $0.63 \times$ $10^{-7} 、 0.88 \times 10^{-7}$ 和 $1.1 \times 10^{-7} \mathrm{~m}^{2} \mathrm{~s}^{-1}$. 不同的体相传质 行为被归因于碳载体形貌导致的催化层孔隙率和孔径 分布的不同. 虽然由于测试方法不同, 不同研究得到的 测试结果略有出人, 但均远小于Bruggeman近似计算得 到的结果.

针对该现象，Cheng等人 ${ }^{[65]}$ 指出，这是由于催化层 内的孔隙尺寸太小, 且孔隙结构复杂多样. 如图6(a) (c) 所示，催化层中存在大量的封闭孔、死孔和细窄通道, 于是造成了无效和低效的气体扩散通路. 只有图6(d)所 示的高效孔道, 才能有效进行体相的氧气传输.

因此, 他们引人了有效孔隙率 $\left(\varepsilon^{\mathrm{eff}}\right)$ 的概念, 对Bruggeman近似公式进行了修正:

$D_{\mathrm{O}_{2}}^{\text {eff }}=D_{\mathrm{O}_{2}}\left(\varepsilon^{\text {eff }}\right)^{1.5}$.

事实上, 对于氧气体相扩散, 最为重要的影响因素 是有效孔隙率，而非几何孔隙率. 有效孔隙率的影响因 素是多样的，如孔径分布、孔道粗䊁度、分形维数等. 此外，Cheng等人 ${ }^{[65]}$ 还发现，当几何孔隙率高达 $60 \%$ 左 右时, 有效孔隙率仅为 $2 \%$ 3\%. 这说明对于催化层结构 优化还有很大的进步空间，可以通过改善孔道分布大 幅降低氧气传质阻力, 提高电池性能, 为将来的研究提 
(a)

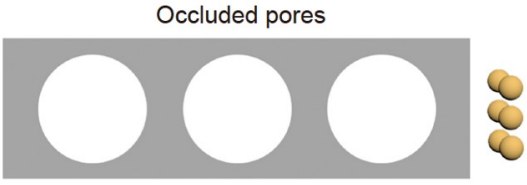

(b)

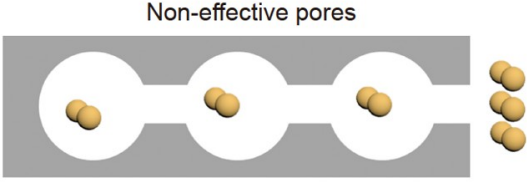

(c)

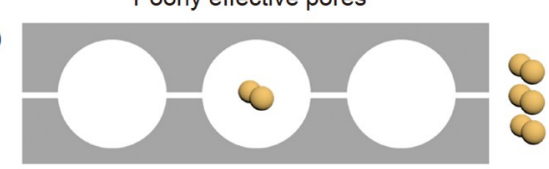

(d)

Highly effective pores

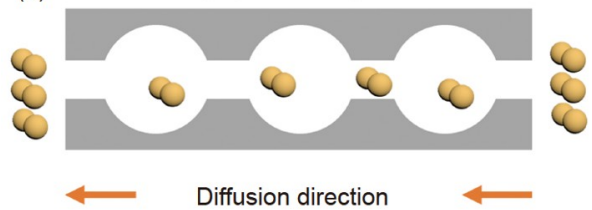

图 6 4种类型的孔隙结构示意图 ${ }^{[65]}$. (a) 封闭孔道; (b) 无效孔道; (c) 低效孔道; (d) 高效孔道

Figure 6 Schematic illustration on four kinds of pore ${ }^{[65]}$. (a) Occluded pores; (b) non-effective pores; (c) poorly effective pores; (d) highly effective pores

供理论依据.

\section{2 低Pt膜电极阴极质子传导特性}

阴极氧还原反应的发生需要氧气、电子和质子的 共同参与，三者缺一不可. 因此，在考虑阴极氧气传输 的同时, 催化层内的质子传导也不容忽视. 从氧气传输 角度来看，催化剂表面的PFSA离子树脂薄膜是造成局 域传质阻力的不利因素, 但从质子传导角度来看, 这层 离子树脂薄膜却是催化层内质子传输的唯一通道. 因 此，低Pt膜电极阴极催化层中质子传导的底层机理和 影响因素值得更加深人地探究.

\section{1 质子传导机理}

对于微米级别的质子交换膜，学者已经进行了相 对充分的研究, 对其内部的纳米结构和质子传输机理 也有了一定的认识. PFSA离子树脂是一种独特的具有 两亲性的树脂, 主链由疏水的非极性碳氟骨架构成, 而 侧链末端连接的极性磺酸基团具有亲水性. 因此, 在 PFSA离子树脂内部会出现亲疏水相的分离：碳氟骨架 团聚形成疏水相, 磺酸基团结合水合氢离子, 并吸引水
分子形成团簇状亲水相, 如图7(a)所示 ${ }^{[66,67]}$.

基于PFSA离子树脂的独特结构，学术界发展出了 两类被广泛认可的质子传导机理: “Grotthuss跃迁”和 “车载”机制。如图7(b)所示，“Grotthuss跃迁”指的是质 子在相邻两个水合氢离子表面的跃迁，是基于树脂矩 阵结构中氢键网络的传输机制 ${ }^{[69,70]}$. 这种机制要求水 分子具有高效的选择和再定位特性，即需要离子树脂 具有较高的水合度 ${ }^{[71,72]}$. 而在低水合度和氢键网络不 完整的情况下, “车载”机制占主导地位, 质子会与水分 子或团簇形成 $\mathrm{H}_{3} \mathrm{O}^{+} 、 \mathrm{H}_{5} \mathrm{O}_{2}{ }^{+}$或 $\mathrm{H}_{9} \mathrm{O}_{4}{ }^{+}$等形式在水分子通 道中迁移 ${ }^{[68,73]}$.

然而，上述PFSA离子树脂的亲疏水相分离结构和 两种质子传输机理，都是基于微米级别的厚膜开展的 研究. 但在燃料电池催化层内, 催化剂颗粒表面的超薄 离子树脂薄膜只有 $5 \sim 10 \mathrm{~nm}$, 其空间结构和物理化学性 质与厚膜有着本质区别, 因此, 质子在其中的传导特性 也会有明显的差异. Decaluwe等人 ${ }^{[74,75]}$ 使用原位中子 反射法检测了不同厚度的Nafion薄膜，发现在不同厚 度区间，Nafion薄膜的形貌具有明显区别：当薄膜厚度 $<12 \mathrm{~nm}$ 时, 膜的厚度小于树脂亲疏水相的区域尺寸, 限 域作用使得薄膜呈片状分布; 当薄膜厚度处于 12 42 nm时，在片状薄膜表面叠加出现一层非片状的 体相形貌的薄膜; 而当薄膜厚度 $>60 \mathrm{~nm}$ 时, 薄膜厚度大 于Nafion树脂的回旋半径, 树脂表现出体相形貌. Zhang 和Ding ${ }^{[76]}$ 经过分子动力学计算发现，在离子树脂内部 靠近Pt表面的区域，树脂密度明显高于外侧区域，而此 处的树脂形貌并不受薄膜厚度和树脂水合度的影响。 Paul等人 ${ }^{[77]}$ 也报道了离子树脂形貌对于薄膜厚度的依 赖性. 此外, 薄膜和厚膜在离子树脂的溶胀特性 ${ }^{[78-80] 、}$ 水含量 ${ }^{[81 ~ 83]}$ 、亲疏水特性 ${ }^{[77,84,85]}$ 、水合度 ${ }^{[86 ~ 88]}$ 、亲疏 水相分布 ${ }^{[89]}$ 、模量 ${ }^{[70,90]}$ 、氧气渗透率 ${ }^{[36-38]}$ 、水分子扩 散速率 ${ }^{[91 ~ 93]}$ 和主侧链分布 ${ }^{[79,94,95]}$ 等物理化学特性方面 也有重要的影响。

厚度对离子树脂薄膜的影响最终体现在质子传导 上. Siroma ${ }^{[96]}$ 制备了 $260 \mathrm{~nm}$ 的Nafion薄膜, 利用微电极 和四点测试法发现, 其质子传导率远低于Nafion 117膜 $(\sim 183 \mu \mathrm{m})$. Paul等人 ${ }^{[97]}$ 制备了 $50 \mathrm{~nm}$ 的Nafion薄膜, 利用 电化学阻抗谱(electrochemical impedance spectroscopy, EIS)测试了其质子传导率和活化能, 发现薄膜的质子传 导活化能明显高于Nafion 112膜( $50 \mu \mathrm{m})$. 因此, 薄膜中 的质子传导机理与厚膜中的有较大区别. 接着, Paul等 人 ${ }^{[77,78,98]}$ 研究了 4 300 $\mathrm{nm}$ 区间内不同厚度的Nafion薄 

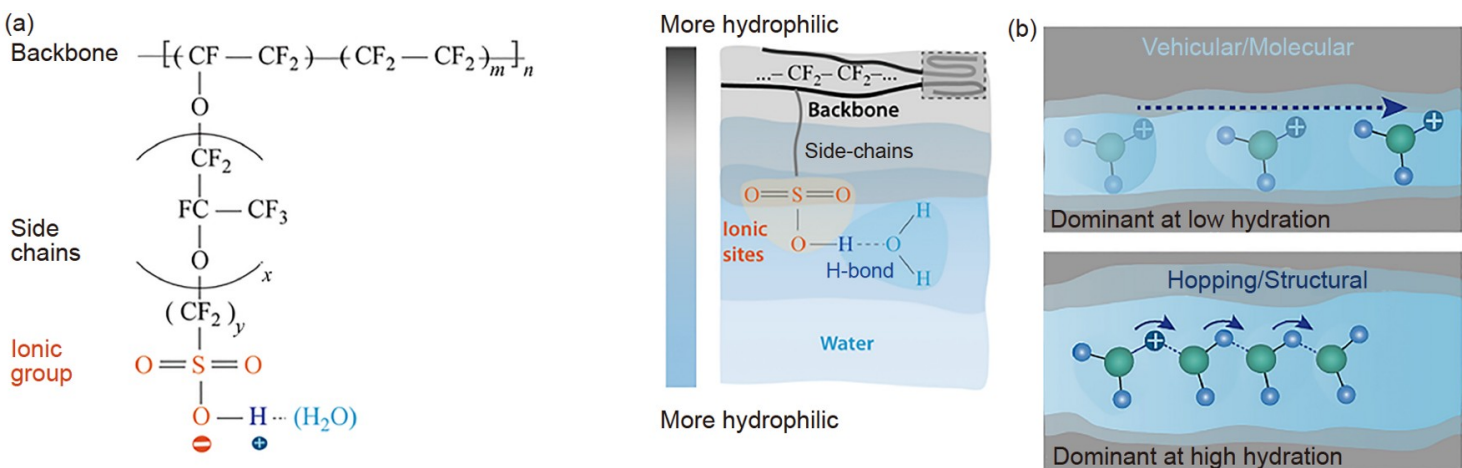

图 7 阴极催化层内的质子传导. (a) PFSA离子树脂微观结构 ${ }^{[67]}$; (b) 两类质子传导机理 ${ }^{[68]}$

Figure 7 Proton transport in CCLs. (a) Nanostructure of PFSA ionomers ${ }^{[67]}$; (b) two types of proton transport mechanism ${ }^{[68]}$

膜，发现薄膜中的质子传导率随薄膜厚度的增大而减 小, 同时活化能随薄膜厚度的增大呈指数性增大. Shen 等人 ${ }^{[99]}$ 通过测试40 120 nm的Nafion薄膜，进一步确认 了这一现象. 他们指出, 不同厚度的Nafion薄膜质子传 导率处于相同量级，都比厚膜的质子传导率低一个量 级, 说明限域作用和树脂形貌改变了薄膜内的质子传 导机理, 但不同厚度的薄膜之间并没有机理性的差异.

\section{2 影响薄膜内质子传导的因素}

同氧气传质类似，催化层内的质子传导也受到环 境、材料和结构等众多因素的影响，只有掌握其变化 规律和反应机理, 才能有针对性地对然料电池进行 优化.

在针对厚膜的研究中，可以确定质子传导率随温 度的增大而增大 ${ }^{[100,101]}$, 但这个规律是否适用于纳米级 别的薄膜却很少有人讨论. 直到Paul等人 ${ }^{[98,99]}$ 和Shen等 人 $^{[99]}$ 利用微观实验证明, 在高湿度下, 超薄Nafion膜内 的质子传导率也随温度的增大而增大. 而且, Shen等 人 $^{[99]}$ 发现, 这个规律不随PFSA离子树脂化学结构和薄 膜厚度的改变而改变. 这是由于高湿度下离子树脂薄 膜处于完全水合的状态, 温度较高时, 质子的运动会加 快, 质子传导阻力就会相应下降.

在PFSA离子树脂的化学组成方面，其当量质量是 一个重要的参数, 厚膜中的质子传导率会随当量质量 的降低而略微增大.

从式(22)可以看出，电导率 $(\sigma)$ 受到电荷载流子浓 度 $(c)$ 、载流子化合价 $(Z)$ 和电荷载流子迁移率 $(\mu)$ 的共 同影响:

$\sigma=c Z e \mu$.
低当量质量的离子树脂具有高离子交换率，也就 意味着具有更大的电荷载流子浓度，因此获得了更高 的 $\sigma$. 式(22)中, $e$ 为基本电荷单位，电荷载流子浓度可 以表示为

$c=\frac{0.01 \rho}{(1+0.01 x) \mathrm{EW}}$,

其中, $\rho$ 为聚合物密度, $x$ 为体积吸水率.

如图8所示，Shen等人 ${ }^{[99]}$ 发现，当薄膜厚度降低至 纳米尺度，膜的质子传导率也随当量质量的减小而增 大，而且增大的幅度会随着温度的升高而提高. 然而, 在图8所示的任一薄膜厚度或任一温度条件下, EW 750 Nafion薄膜的质子传导率都比EW 1100 Nafion薄 膜高约2倍. 根据式(22)和(23), 当量质量对电荷载流子 浓度的影响并没有达到2倍. 因此, Shen等人 ${ }^{[99]}$ 推测, 在 纳米尺度的薄膜中, PFSA离子树脂的当量质量不仅影 响电荷载流子浓度, 也对电荷载流子迁移率有着重要 的影响. 他们利用掠人射X射线小角散射(grazing incident small angle X-ray scattering, GISAXS)对不同当量 质量的Nafion薄膜进行表征, 验证了这个猜想. 在当量 质量较低时, 薄膜内的亲疏水相发生明显的分离, 水分 子聚集为质子提供了传输通道; 而在当量质量较高时, 亲疏水相分离减弱, 质子传输通道受阻, 质子传导率也 相应下降.

此外，配制浆料是膜电极成型工艺中的重要一环， 浆料组分的选择和配比在催化剂活性、质子传导和氧 气传输等多方面都具有重要的影响，是燃料电池性能 的决定因素. 浆料中的溶剂会影响离子树脂在浆料中 的分布形态和团聚状态 ${ }^{[102 ~ 105]}$, 进而影响催化层成型后 的形貌和传质特性. Affoune等人 ${ }^{[106]}$ 对比了甲醇、乙 

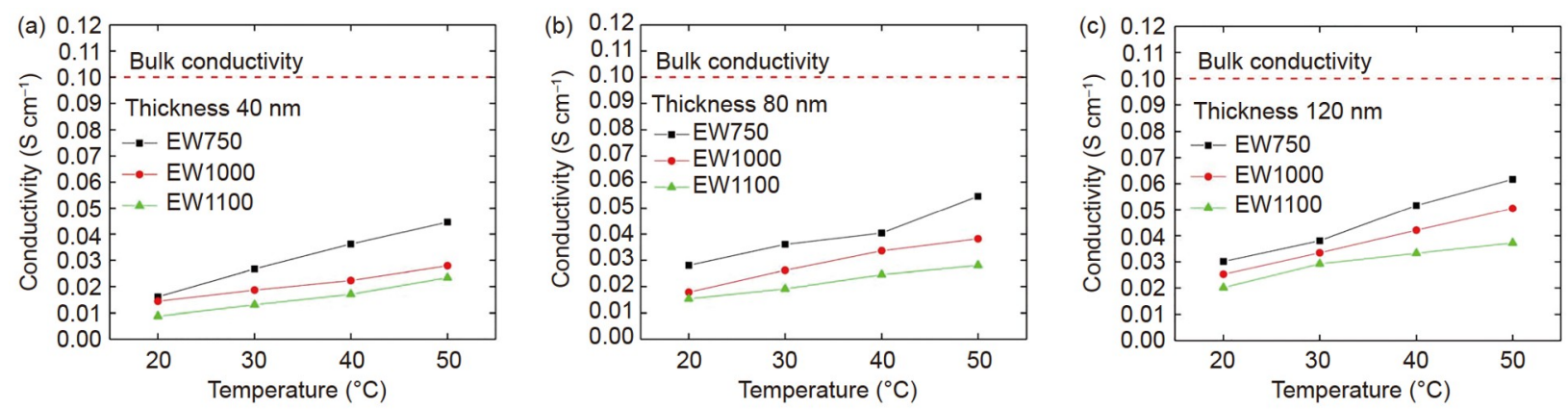

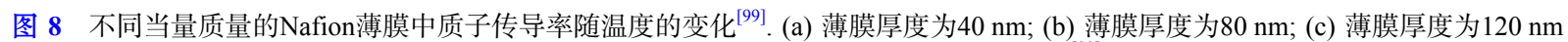
Figure 8 Proton conductivity in Nafion films with different EWs as a function of temperature ${ }^{[99]}$. (a) Film thickness is $40 \mathrm{~nm}$; (b) film thickness is $80 \mathrm{~nm}$; (c) film thickness is $120 \mathrm{~nm}$

醇、正丙醇和水对Nafion厚膜质子传导和表面性质的 影响, 发现Nafion在醇类环境中表现出更平坦的表面形 貌和更低的质子传导率. Han等人 ${ }^{[107]}$ 使用乙酸丁酯、 乙酸乙酯、正丁醇、异丙醇、正丙醇、乙醇、甲醇、 $N$-甲基-2-吡咯烷酮、二甲基亚砜和水作为溶剂, 对 $\mathrm{Na}-$ fion的成膜性进行了研究. 他们发现, 使用极性过小的 乙酸丁酯和乙酸乙酯作为溶剂无法分散Nafion, 而使用 极性过大的乙醇、甲醇、 $N$-甲基-2-吡咯烷酮、二甲基 亚砜和水作为溶剂由于表面张力无法成膜. 而在正丁 醇、异丙醇和正丙醇中, 以低介电常数的正丁醇制备 的Nafion薄膜具有更高的质子传导率和更低的活化能， 而高介电常数的正丙醇则制备得到了低质子传导率和 高活化能的Nafion薄膜. 这是因为Nafion的全氟骨架在 低极性溶剂中更易溶解，主链和侧链均具有更高的迁 移率, 因而可形成更为连贯的胶束, 为质子传导提供高 效通道.

另一方面，由于Pt合金(Pt-M)催化剂的广泛使

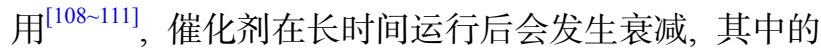
合金元素会溶出并污染催化层中的离子树脂和阴阳极 之间的质子交换膜 ${ }^{[12 ~ 114]}$, 也会严重影响催化层内的质 子传导. 已有研究证明, 在厚膜中金属阳离子的污染会 大幅提高质子传导的活化能，降低质子传导率 ${ }^{[115,116]}$ 金属离子比水合氢离子更容易与磺酸基团结合，而阳 离子-水簇的迁移率远远小于水合氢离子簇的迁移率, 会堵塞质子传导的通道，阻碍质子传输. 然而，金属阳 离子掺杂的影响对于纳米级别的薄膜更为致命. Han等 人 ${ }^{[117]}$ 研究了不同污染程度的Nafion薄膜，发现钴离子 对薄膜中质子传导率的影响远大于厚膜，当薄膜中的 磺酸基团上的质子位点有一半以上被钴离子取代后, 其活化能大幅上升, 质子传导率明显下降. 这是由于钴
离子的占位效应导致Nafion薄膜中的电荷载流子浓度 和电荷载流子迁移率同时下降(式(22))，再加上超薄膜 中限域作用导致的相分离减弱，进一步强化了金属阳 离子掺杂导致的后果.

\section{3 总结与展望}

质子交换膜燃料电池正朝着产业应用迅猛发展, 膜电极低Pt化是必须迈出的重要一步, 而低Pt化带来的 膜电极中的一系列关键问题需要科学的理解和理性的 应对.

首先，低Pt化带来更加明显的阴极氧气传质阻力, 会明显降低大电流区的电池性能. 阴极氧气传质阻力 主要来源于催化层内的传质，Pt载量的降低会导致催 化活性位点减少, 大幅提高局域传质阻力, 所以阐明局 域传质机理并针对性地进行改进至关重要. 此外, 催化 层内的孔隙结构同样影响着体相传质. 实验表明, 目前 普遍使用的多孔催化层中的孔隙利用率过低，如果能 够设计制造出合适的催化层微观结构，也可以明显改 善阴极氧气传质, 达到补偿浓差极化的目的. 值得一提 的是, 低Pt化导致的催化层传质阻力同时也会加速催化 剂的衰减，其后果是多方面的，需要协同应对. 未来的 研究可以进一步探究催化层内的局域和体相氧气传质 机理, 并针对电池性能和寿命进行结构优化.

其次, 催化层内的质子传导依赖超薄离子树脂. 离 子树脂薄膜的厚度限制了质子传导率，不仅降低了电 荷载流子浓度, 更重要的是影响了电荷载流子的迁移 率, 这与传统的厚膜在机理上有着本质区别. 未来的研 究可以从离子树脂的化学组成、微观形貌、分散状态 和薄膜的体相分布等多角度进行研究和改进，并分析 其“构-效”机理. 


\section{参考文献}

1 Ministry of Industry and Information Technology of the People's Republic of China. New Energy Vehicle Promotion and Application Recommended Model Catalog (2020-11) (in Chinese). Technical Report, 2020 [中华人民共和国工业和信息化部. 新能源汽车推广应用推荐车 型目录(2020年第11批). 科技报告, 2020]

2 Toyota. 2020 Toyota Mirai Fuel Cell Electric Vehicle Power to Start Something Bigger. Technical Report, 2020

3 The United States Department of Energy. Hydrogen and Fuel Cell Technologies Office Multi-Year Research, Development, and Demonstration Plan. Technical Report, 2017

4 The United States Department of Energy. Automotive Fuel Cell Targets and Status. Technical Report, 2020

5 The United States Department of Energy. Durability-adjusted Fuel Cell System Cost. Technical Report, 2021

6 Hydrogen Council. Hydrogen Meets Digital. Technical Report, 2018

7 Kongkanand A, Mathias M F. The priority and challenge of high-power performance of low-platinum proton-exchange membrane fuel cells. J Phys Chem Lett, 2016, 7: 1127-1137

8 Wang C, Zhang Q, Lu J, et al. Effect of height/width-tapered flow fields on the cell performance of polymer electrolyte membrane fuel cells. Int J Hydrog Energy, 2017, 42: 23107-23117

9 Baker D R, Caulk D A, Neyerlin K C, et al. Measurement of oxygen transport resistance in PEM fuel cells by limiting current methods. J Electrochem Soc, 2009, 156: B991

10 Aiyejina A, Sastry M K S. PEMFC flow channel geometry optimization: A review. J Fuel Cell Sci Technol, 2011, 9: 011011

11 Selvaraj A S, Rajagopal T K R. Numerical investigation on the effect of flow field and landing to channel ratio on the performance of PEMFC. Int J Energy Res, 2020, 44: 171-191

12 Yoon Y G, Lee W Y, Park G G, et al. Effects of channel configurations of flow field plates on the performance of a PEMFC. Electrochim Acta, 2004, 50: 709-712

13 Yoon Y, Lee W, Park G, et al. Effects of channel and rib widths of flow field plates on the performance of a PEMFC. Int J Hydrog Energy, 2005, 30: $1363-1366$

14 Shimpalee S, Vanzee J. Numerical studies on rib \& channel dimension of flow-field on PEMFC performance. Int J Hydrog Energy, 2007, 32 $842-856$

15 Wang C, Zhang Q, Shen S, et al. The respective effect of under-rib convection and pressure drop of flow fields on the performance of PEM fuel cells. Sci Rep, 2017, 7: 43447

16 Li W, Zhang Q, Wang C, et al. Experimental and numerical analysis of a three-dimensional flow field for PEMFCs. Appl Energy, 2017, 195: 278288

17 Yan X, Guan C, Zhang Y, et al. Flow field design with 3D geometry for proton exchange membrane fuel cells. Appl Therm Eng, 2019, 147: 11071114

18 Hottinen T, Himanen O. PEMFC temperature distribution caused by inhomogeneous compression of GDL. Electrochem Commun, 2007, 9: 10471052

19 Sun W, Peppley B A, Karan K. Modeling the influence of GDL and flow-field plate parameters on the reaction distribution in the PEMFC cathode catalyst layer. J Power Sources, 2005, 144: 42-53

20 Ko D, Doh S, Park H S, et al. The effect of through plane pore gradient GDL on the water distribution of PEMFC. Int J Hydrog Energy, 2018, 43: $2369-2380$

21 Chen T, Liu S, Zhang J, et al. Study on the characteristics of GDL with different PTFE content and its effect on the performance of PEMFC. Int J Heat Mass Transf, 2019, 128: 1168-1174

22 Wang $\mathrm{C}$, Cheng $\mathrm{X}, \mathrm{Lu} \mathrm{J}$, et al. The experimental measurement of local and bulk oxygen transport resistances in the catalyst layer of proton exchange membrane fuel cells. J Phys Chem Lett, 2017, 8: 5848-5852

23 Mashio T, Ohma A, Yamamoto S, et al. Analysis of reactant gas transport in a catalyst layer. ECS Trans, 2007, 11: 529-540

24 Sakai K, Sato K, Mashio T, et al. Analysis of reactant gas transport in catalyst layers effect of Pt-loadings. ECS Trans, 2009, 25: 1193-1201

25 Ono Y, Mashio T, Takaichi S, et al. The analysis of performance loss with low platinum loaded cathode catalyst layers. ECS Trans, 2010, 28: 6978

26 Iden H, Takaichi S, Furuya Y, et al. Relationship between gas transport resistance in the catalyst layer and effective surface area of the catalyst. J Electroanal Chem, 2013, 694: 37-44

27 Nonoyama N, Okazaki S, Weber A Z, et al. Analysis of oxygen-transport diffusion resistance in proton-exchange-membrane fuel cells. J Electrochem Soc, 2011, 158: B416

28 Greszler T A, Caulk D, Sinha P. The impact of platinum loading on oxygen transport resistance. J Electrochem Soc, 2012, 159: F831-F840 
29 Owejan J P, Owejan J E, Gu W. Impact of platinum loading and catalyst layer structure on PEMFC performance. ECS Trans, 2013, 160: F824F833

30 Orfanidi A, Madkikar P, El-Sayed H A, et al. The key to high performance low Pt loaded electrodes. J Electrochem Soc, 2017, 164: F418-F426

31 Schuler T, Chowdhury A, Freiberg A T, et al. Fuel-cell catalyst-layer resistance via hydrogen limiting-current measurements. J Electrochem Soc, 2019, 166: F3020-F3031

32 Shen S, Cheng X, Wang C, et al. Exploration of significant influences of the operating conditions on the local $\mathrm{O}_{2}$ transport in proton exchange membrane fuel cells (PEMFCs). Phys Chem Chem Phys, 2017, 19: 26221-26229

33 Suzuki T, Kudo K, Morimoto Y. Modeling of oxygen transport resistance in polyme electrolyte fuel cell. R\&D Rev Toyota CTDL, 2018, 49: 1319

34 Kudo K, Suzuki T, Morimoto Y. Analysis of oxygen dissolution rate from gas phase into Nafion surface and development of an agglomerate model. ECS Trans, 2010, 33: 1495-1502

35 Kudo K, Morimoto Y. Analysis of oxygen transport resistance of Nafion thin film on pt electrode. ECS Trans, 2013, 50: 1487-1494

36 Suzuki T, Kudo K, Morimoto Y. Model for investigation of oxygen transport limitation in a polymer electrolyte fuel cell. J Power Sources, 2013, 222: 379-389

37 Kudo K, Jinnouchi R, Morimoto Y. Humidity and temperature dependences of oxygen transport resistance of Nafion thin film on platinum electrode. Electrochim Acta, 2016, 209: 682-690

38 Jinnouchi R, Kudo K, Kitano N, et al. Molecular dynamics simulations on $\mathrm{O}_{2}$ permeation through Nafion ionomer on platinum surface. Electrochim Acta, 2016, 188: 767-776

39 Weber A Z, Kusoglu A. Unexplained transport resistances for low-loaded fuel-cell catalyst layers. J Mater Chem A, 2014, 2: 17207-17211

40 Kurihara Y, Mabuchi T, Tokumasu T. Molecular simulation of oxygen permeation through ionomer in catalyst layer. ECS Trans, 2014, 64: 559565

41 Sugaya Y, Tokumasu T. Molecular dynamics study of oxygen permeation of ionomer of hydrocarbon. ECS Trans, 2013, 58: 1165-1174

42 Ono Y, Ohma A, Shinohara K, et al. Influence of equivalent weight of ionomer on local oxygen transport resistance in cathode catalyst layers. J Electrochem Soc, 2013, 160: F779-F787

$43 \mathrm{Su}$ W Y, Wang S M, Cheng S H. Electrochemically pretreated screen-printed carbon electrodes for the simultaneous determination of aminophenol isomers. J Electroanal Chem, 2011, 651: 166-172

44 Takamura Y, Nakashima E, Yamada H, et al. Effects of temperature and relative humidity on oxygen permeation in Nafion ${ }^{\circledR}$ and sulfonated poly (arylene ether sulfone). ECS Trans, 2008, 16: 881-889

45 Novitski D, Holdcroft S. Determination of $\mathrm{O}_{2}$ mass transport at the Pt $\mid$ PFSA ionomer interface under reduced relative humidity. ACS Appl Mater Interfaces, 2015, 7: 27314-27323

46 Chowdhury A, Radke C J, Weber A Z. Transport resistances in fuel-cell catalyst layers. ECS Trans, 2017, 80: 321-333

47 Wang C, Cheng X, Yan X, et al. Respective influence of ionomer content on local and bulk oxygen transport resistance in the catalyst layer of PEMFCs with low Pt loading. J Electrochem Soc, 2019, 166: F239-F245

48 Katzenberg A, Chowdhury A, Fang M, et al. Highly permeable perfluorinated sulfonic acid ionomers for improved electrochemical devices: Insights into structure-property relationships. J Am Chem Soc, 2020, 142: 3742-3752

49 Cheng X, Wei G, Wang C, et al. Experimental probing of effects of carbon support on bulk and local oxygen transport resistance in ultra-low Pt PEMFCs. Int J Heat Mass Transf, 2021, 164: 120549

50 Ott S, Orfanidi A, Schmies H, et al. Ionomer distribution control in porous carbon-supported catalyst layers for high-power and low Pt-loaded proton exchange membrane fuel cells. Nat Mater, 2020, 19: 77-85

51 Sun X, Yu H, Zhou L, et al. Influence of platinum dispersity on oxygen transport resistance and performance in PEMFC. Electrochim Acta, 2020, 332: 135474

52 Yarlagadda V, Carpenter M K, Moylan T E, et al. Boosting fuel cell performance with accessible carbon mesopores. ACS Energy Lett, 2018, 3: $618-621$

53 Iden H, Ohma A. An in situ technique for analyzing ionomer coverage in catalyst layers. J Electroanal Chem, 2013, 693: 34-41

54 Ito T, Matsuwaki U, Otsuka Y, et al. Three-dimensional spatial distributions of Pt catalyst nanoparticles on carbon substrates in polymer electrolyte fuel cells. Electrochemistry, 2011, 79: 374-376

55 Mashio T, Iden H, Ohma A, et al. Modeling of local gas transport in catalyst layers of PEM fuel cells. J Electroanal Chem, 2017, 790: 27-39

56 Liang J, Li Y, Wang R, et al. Cross-dimensional model of the oxygen transport behavior in low-Pt proton exchange membrane fuel cells. Chem Eng J, 2020, 400: 125796

57 Bruggeman D A G. Berechnung verschiedener physikalischer Konstanten von heterogenen Substanzen. I. Dielektrizitätskonstanten und Leitfähigkeiten der Mischkörper aus isotropen Substanzen. Ann Phys, 1935, 416: 636-664 
58 Tjaden B, Cooper S J, Brett D J, et al. On the origin and application of the Bruggeman correlation for analysing transport phenomena in electrochemical systems. Curr Opin Chem Eng, 2016, 12: 44-51

59 Lange K J, Sui P C, Djilali N. Pore scale modeling of a proton exchange membrane fuel cell catalyst layer: Effects of water vapor and temperature. J Power Sources, 2011, 196: 3195-3203

60 Suzuki A, Sen U, Hattori T, et al. Ionomer content in the catalyst layer of polymer electrolyte membrane fuel cell (PEMFC): Effects on diffusion and performance. Int J Hydrog Energy, 2011, 36: 2221-2229

61 Kreuer K D, Rabenau A, Weppner W. Vehicle mechanism, a new model for the interpretation of the conductivity of fast proton conductors. Angew Chem Int Edit, 1982, 21: 208-209

62 Shen J, Zhou J, Astrath N G C, et al. Measurement of effective gas diffusion coefficients of catalyst layers of PEM fuel cells with a Loschmidt diffusion cell. J Power Sources, 2011, 196: 674-678

63 Yu Z, Carter R N, Zhang J. Measurements of pore size distribution, porosity, effective oxygen diffusivity, and tortuosity of PEM fuel cell electrodes. Fuel Cells, 2012, 12: 557-565

64 Yu Z, Carter R N. Measurement of effective oxygen diffusivity in electrodes for proton exchange membrane fuel cells. J Power Sources, 2010, 195: $1079-1084$

65 Cheng X, Wang C, Wei G, et al. Insight into the effect of pore-forming on oxygen transport behavior in ultra-low Pt PEMFCs. J Electrochem Soc, 2019, 166: F1055-F1061

66 Mauritz K A, Moore R B. State of understanding of Nafion. Chem Rev, 2004, 104: 4535-4586

67 Haubold H G, Vad T, Jungbluth H, et al. Nano structure of Nafion: A SAXS study. Electrochim Acta, 2001, 46: 1559-1563

68 Kusoglu A, Weber A Z. New insights into perfluorinated sulfonic-acid ionomers. Chem Rev, 2017, 117: 987-1104

69 Agmon N. The Grotthuss mechanism. Chem Phys Lett, 1995, 244: 456-462

70 Page K A, Kusoglu A, Stafford C M, et al. Confinement-driven increase in ionomer thin-film modulus. Nano Lett, 2014, 14: 2299-2304

71 Kreuer K D. On the development of proton conducting polymer membranes for hydrogen and methanol fuel cells. J Membrane Sci, 2001, 185: 29-39

72 Kreuer K D. On the development of proton conducting materials for technological applications. Solid State Ion, 1997, 97: 1-15

73 Liu L, Chen W, Li Y. An overview of the proton conductivity of Nafion membranes through a statistical analysis. J Membrane Sci, 2016, 504: 1-9

74 Kusoglu A. Ionomer Thin Films in PEM Fuel Cells. New York: Springer, 2018. 1-23

75 DeCaluwe S C, Baker A M, Bhargava P, et al. Structure-property relationships at Nafion thin-film interfaces: Thickness effects on hydration and anisotropic ion transport. Nano Energy, 2018, 46: 91-100

76 Zhang X, Ding Y. Thickness-dependent structural and transport behaviors in the platinum-Nafion interface: A molecular dynamics investigation. RSC Adv, 2014, 4: 44214-44222

77 Paul D K, Karan K, Docoslis A, et al. Characteristics of self-assembled ultrathin Nafion films. Macromolecules, 2013, 46: 3461-3475

78 Kusoglu A, Kushner D, Paul D K, et al. Impact of substrate and processing on confinement of Nafion thin films. Adv Funct Mater, 2014, 24: $4763-4774$

79 Eastman S A, Kim S, Page K A, et al. Effect of confinement on structure, water solubility, and water transport in Nafion thin films. Macromolecules, 2012, 45: 7920-7930

80 Dishari S K, Hickner M A. Antiplasticization and water uptake of Nafion thin films. ACS Macro Lett, 2012, 1: 291-295

81 Kusoglu A, Dursch T J, Weber A Z. Nanostructure/swelling relationships of bulk and thin-film PFSA ionomers. Adv Funct Mater, 2016, 26: 4961-4975

82 Kongkanand A. Interfacial water transport measurements in Nafion thin films using a quartz-crystal microbalance. J Phys Chem C, 2011, 115: $11318-11325$

83 Bertoncello P, Ciani I, Li F, et al. Measurement of apparent diffusion coefficients within ultrathin Nafion Langmuir-Schaefer films: Comparison of a novel scanning electrochemical microscopy approach with cyclic voltammetry. Langmuir, 2006, 22: 10380-10388

84 Bass M, Berman A, Singh A, et al. Surface structure of Nafion in vapor and liquid. J Phys Chem B, 2010, 114: 3784-3790

85 Mohamed H F M, Kuroda S, Kobayashi Y, et al. Possible presence of hydrophilic $\mathrm{SO}_{3} \mathrm{H}$ nanoclusters on the surface of dry ultrathin Nafion ${ }^{\circledR}$ films: A positron annihilation study. Phys Chem Chem Phys, 2013, 15: 1518-1525

86 Shim H K K, Paul D K, Karan K. Resolving the contradiction between anomalously high water uptake and low conductivity of nanothin Nafion films on $\mathrm{SiO}_{2}$ substrate. Macromolecules, 2015, 48: 8394-8397

87 Ozhukil Kollath V, Karan K. New molecular scale insights into the $\alpha$-transition of Nafion ${ }^{\circledR}$ thin films from variable temperature ATR-FTIR spectroscopy. Phys Chem Chem Phys, 2016, 18: 26144-26150

88 Abiko K, Kato Y. Analysis of the molecular orientation of poly(3-hexylthiophene) on silicon treated with silane coupling agents, by infrared ppolarized multiple-angle incidence resolution spectrometry. Chem Lett, 2018, 47: 332-335 
89 Paul D K, Shim H K K, Giorgi J B, et al. Thickness dependence of thermally induced changes in surface and bulk properties of Nafion ${ }^{\circledR}$ nanofilms. J Polym Sci Part B-Polym Phys, 2016, 54: 1267-1277

90 Page K A, Shin J W, Eastman S A, et al. In situ method for measuring the mechanical properties of Nafion thin films during hydration cycles. ACS Appl Mater Interfaces, 2015, 7: 17874-17883

91 Ogata Y, Kawaguchi D, Yamada N L, et al. Multistep thickening of Nafion thin films in water. ACS Macro Lett, 2013, 2: 856-859

92 Davis E M, Stafford C M, Page K A. Elucidating water transport mechanisms in Nafion thin films. ACS Macro Lett, 2014, 3: 1029-1035

93 Bertoncello P, Wilson N R, Unwin P R. One-step formation of ultra-thin chemically functionalized redox-active Langmuir-Schaefer Nafion films. Soft Matter, 2007, 3: 1300-1307

94 Bass M, Berman A, Singh A, et al. Surface-induced micelle orientation in Nafion films. Macromolecules, 2011, 44: $2893-2899$

95 Noguchi H, Taneda K, Minowa H, et al. Humidity-dependent structure of surface water on perfluorosulfonated ionomer thin film studied by sum frequency generation spectroscopy. J Phys Chem C, 2010, 114: 3958-3961

96 Siroma Z. Proton conductivity along interface in thin cast film of Nafion ${ }^{\circledR}$. Electrochem Commun, 2002, 4: 143-145

97 Paul D K, Fraser A, Karan K. Towards the understanding of proton conduction mechanism in PEMFC catalyst layer: Conductivity of adsorbed Nafion films. Electrochem Commun, 2011, 13: 774-777

98 Paul D K, McCreery R, Karan K. Proton transport property in supported Nafion nanothin films by electrochemical impedance spectroscopy. J Electrochem Soc, 2014, 161: F1395-F1402

99 Shen S, Han A, Yan X, et al. Influence of equivalent weight of ionomer on proton conduction behavior in fuel cell catalyst layers. J Electrochem Soc, 2019, 166: F724-F728

100 Casciola M, Alberti G, Sganappa M, et al. On the decay of Nafion proton conductivity at high temperature and relative humidity. J Power Sources, 2006, 162: 141-145

101 Luo Z, Chang Z, Zhang Y, et al. Electro-osmotic drag coefficient and proton conductivity in Nafion ${ }^{\circledR}$ membrane for PEMFC. Int J Hydrog Energy, 2010, 35: 3120-3124

102 Ngo T T, Yu T L, Lin H L. Influence of the composition of isopropyl alcohol/water mixture solvents in catalyst ink solutions on proton exchange membrane fuel cell performance. J Power Sources, 2013, 225: 293-303

103 Lee S J, Yu T L, Lin H L, et al. Solution properties of Nafion in methanol/water mixture solvent. Polymer, 2004, 45: 2853-2862

104 Ma C H, Yu T L, Lin H L, et al. Morphology and properties of Nafion membranes prepared by solution casting. Polymer, 2009, 50: 1764-1777

105 Zhang H, Pan J, He X, et al. Zeta potential of Nafion molecules in isopropanol-water mixture solvent. J Appl Polym Sci, 2008, 107: 3306-3309

106 Affoune A M, Yamada A, Umeda M. Conductivity and surface morphology of Nafion membrane in water and alcohol environments. J Power Sources, 2005, 148: 9-17

107 Han A, Yan X, Chen J, et al. Effects of dispersion solvents on proton conduction behavior of ultrathin Nafion films in the catalyst layers of proton exchange membrane fuel cells. Acta Phys-Chim Sin, 2020, 36: 1912052

108 Yoshida T, Kojima K J. Toyota MIRAI fuel cell vehicle and progress toward a future hydrogen society. Electrochem Soc Interface, 2015, 24: 45-49

109 Tian R, Shen S, Zhu F, et al. Icosahedral Pt-Ni nanocrystalline electrocatalyst: Growth mechanism and oxygen reduction activity. ChemSusChem, 2018, 11: 1015-1019

110 Luo L, Zhu F, Tian R, et al. Composition-graded $\mathrm{Pd}_{x} \mathrm{Ni}_{1-x}$ nanospheres with Pt monolayer shells as high-performance electrocatalysts for oxygen reduction reaction. ACS Catal, 2017, 7: 5420-5430

111 Luo X, Guo Y, Zhou H, et al. Thermal annealing synthesis of double-shell truncated octahedral Pt-Ni alloys for oxygen reduction reaction of polymer electrolyte membrane fuel cells. Front Energy, 2020, 14: 767-777

112 Zhu F, Wu A, Luo L, et al. The asymmetric effects of $\mathrm{Cu}^{2+}$ contamination in a proton exchange membrane fuel cell (PEMFC). Fuel Cells, 2020, 20: $196-202$

113 Zheng Z, Luo L, Zhu F, et al. Degradation of core-shell $\mathrm{Pt}_{3}$ Co catalysts in proton exchange membrane fuel cells (PEMFCs) studied by mathematical modeling. Electrochim Acta, 2019, 323: 134751

114 Colón-Mercado H R, Popov B N. Stability of platinum based alloy cathode catalysts in PEM fuel cells. J Power Sources, 2006, 155: 253-263

115 Cai Y, Kongkanand A, Gu W, et al. Effects of cobalt cation on low Pt-loaded PEM fuel cell performance. ECS Trans, 2015, 69: 1047-1061

116 Hongsirikarn K, Goodwin Jr J G, Greenway S, et al. Effect of cations $\left(\mathrm{Na}^{+}, \mathrm{Ca}^{2+}, \mathrm{Fe}^{3+}\right)$ on the conductivity of a Nafion membrane. J Power Sources, 2010, 195: 7213-7220

117 Han A, Fu C, Yan X, et al. Effect of cobalt ion contamination on proton conduction of ultrathin Nafion film. Int J Hydrog Energy, 2020, 45: $25276-25285$

118 Jiang J, Li Y, Liang J, et al. Modeling of high-efficient direct methanol fuel cells with order-structured catalyst layer. Appl Energy, 2019, 252: 113431 


\title{
Analysis and outlook of mass transport in ultralow Pt loading proton exchange membrane fuel cells
}

\author{
Xiaojing Cheng ${ }^{1}$, Shuiyun Shen $^{1}$, Chao Wang ${ }^{1}$, Xiaohui Yan $^{1} \&$ Junliang Zhang ${ }^{1,2^{*}}$ \\ ${ }^{1}$ Institute of Fuel Cells, School of Mechanical Engineering, Shanghai Jiao Tong University, Shanghai 200240, China; \\ ${ }^{2}$ Key Laboratory of Power Machinery \& Engineering of Ministry of Education, Shanghai Jiao Tong University, Shanghai 200240, China \\ * Corresponding author, E-mail: junliang.zhang@sjtu.edu.cn
}

Proton exchange membrane fuel cells (PEMFCs) for automotive propulsions have been regarded as an ideal and the most promising alternative to replace fossil-fuel based internal combustion engines due to the high performance, high energy efficiency and zero-emission. However, the high cost has severely impeded the commercialization of PEMFCs, especially the high cost of Pt-based precious metal catalyst used for the cathode oxygen reduction reaction (ORR). It is critical to reducing the amount of $\mathrm{Pt}$ and thus decreasing the cost of fuel cell stacks, which would lead to numbers of new challenges.

On the one hand, the reduction of Pt load could increase the oxygen transport resistance in cathode catalyst layers (CCLs). In fact, the oxygen transport resistance could be divided into several constituent parts, i.e., oxygen transport resistances in CCLs, gas diffusion layers (GDLs) and the flow channels, where the transport resistance in CCLs is much higher than other resistances. Further, CCLs are constructed as heterogeneous composites of ORR electrocatalysts, conductive polymer such as perfluorinated sulfonic acid (PFSA) ionomer as well as the pore space determined. Hence, the oxygen transport resistance in CCLs includes the bulk transport resistance caused by oxygen diffusion in the nanopore and the local transport resistance caused by oxygen permeation through the ultrathin ionomer film covering on the Pt surface.

Local oxygen transport behavior could be divided into three processes: (1) Oxygen adsorption from gas phase into ionomer, (2) oxygen diffusion inside the ionomer, and (3) oxygen adsorption from the ionomer to Pt surfaces. As the Pt loading decreases, local oxygen transport resistance would increase significantly, thus leading to a dramatical performance degradation at high current density of fuel cells. In specific, the oxygen adsorption at gas/ionomer interface used to be considered as Henry's adsorption. However, it is proved recently that this type of adsorption should be quasi-logarithmic, due to the finiteness of the adsorption site on ionomer surface.

In addition, the bulk oxygen transport resistance depends on the porosity and pore size distribution inside the electrodes. We summarized plenty of experimental results of effective oxygen diffusivities reported by different research groups, and found that all the experimental values are obviously smaller than the calculated results based on the classical Bruggeman approximation. It is believed that the effective porosity plays a more important role relative to the geometrical porosity in the estimation of bulk oxygen transport resistance in PEMFCs.

On the other hand, confining effect of the ultrathin ionomer film could weaken the separation of hydrophilic and hydrophobic phases and then cut down the pathway of proton migration. There are two proton conduction mechanisms in CCLs: Grotthuss hopping and vehicular mechanism. The proton conduction in CCLs could be affected by numerous factors, such as temperature, ionomer structure, thickness of ionomer film, as well as cation contaminants in the ionomer film.

Both high oxygen transport resistance and low proton conduction in ultra-low Pt membrane electrode assemblies would damage the performance and the lifetime of PEMFCs. In this review, the bulk and local transport behavior, proton transport in CCLs, as well as the corresponding influence on fuel cell performance are systematically analyzed, and a series of coping strategies are presented.

ultralow Pt loading, mass transport at cathode, local transport resistance, bulk transport resistance, proton transport

doi: 10.1360/TB-2021-0148 